\title{
Standards and the Incentives for Innovation
}

\author{
by \\ Troy J. Scott \\ Research Economist \\ RTI International \\ Research Triangle Park, NC 27709 \\ U.S.A. \\ and \\ John T. Scott \\ Professor of Economics \\ Dartmouth College \\ Hanover, NH 03755 \\ U.S.A.
}

January 2013 v1.18.13

\begin{abstract}
We model the economics of the effects of standards on incentives for innovative investment. We use survey data from industrial respondents to parameterize our model, allowing us to explain and predict effects of technology standards on investment in the development of technology and thereby assess the benefits and costs of technology standards in a market equilibrium setting. Having parameterized the model with the responses of industry to our survey, we can also describe the differences in effects of standards for different types of firms and for different types of industrial research, and we can simulate the effects of stronger or weaker intellectual property (IP) protection, using the industrial responses to answer the question of how the opposing effects from changes in IP protection on balance affect innovative investments. We find that the net effects of standards for IP protection are positive, increasing innovative investments and increasing their private and social value.
\end{abstract}

Prepared for the

Research Roundtable Conference on Technology Standards and Innovation

The Searle Center on Law, Regulation, and Economic Growth

Northwestern University School of Law in Chicago, IL

February 7-8, 2013. 


\section{Standards and the Incentives for Innovation}

\section{Introduction}

In this paper, we model the economics of the effects of standards on incentives for innovative investment. We then use survey data from industrial respondents to parameterize our model, allowing us to explain and predict effects of technology standards on investment in the development of technology and thereby assess the benefits and costs of technology standards in a market equilibrium setting. Having parameterized the model with the responses of industry to our survey, we can also describe the differences in effects of standards for different types of firms and for different types of industrial research, and we can simulate the effects of stronger or weaker intellectual property (IP) protection associated with standards, using the industrial responses to answer the question of how the opposing effects from changes in IP protection on balance affect innovative investments.

Our paper is concerned with the effects of standards on economic incentives and economic performance. Our theory and our field work encompass a wide range of important standards, including standards for the physical characteristics of products (e.g., USB ports) and services (e.g., protocols allowing exchange of data in high-speed communications networks) as well as standards for measurement (e.g., thermocouple calibration for the accurate measurement of temperature, traceable to a national or international standard). ${ }^{1}$

In the context of understanding the impact of the standards on investments in technology development, the two concepts of standards-measurement standards and product standards - are similar in that both allow competitors to compete with directly comparable products. In terms of our model, both types of standards have what we describe as value-shifting and (probability) distribution-shifting effects for the firm making innovative investments.

For example, each competitor selling a computer will be selling a product that will be compatible with all products (goods and services) needing to use the computer's USB port, and each competitor selling a device connecting to computers via the USB ports will be able to connect, and in these cases then consumers can know all of the products will work with regard to the USB connection and so all sellers can compete with their proprietary products and services, all of which conform to the standard. Now compare a standard that allows measurements traceable to a standard maintained in a national laboratory. For concreteness, consider the standard reference material (SRM) allowing accurate measurement of the wavelength of light. ${ }^{2}$ Sellers of the equipment that

\footnotetext{
${ }^{1}$ See Tassey (1997) and Link and Tassey (1987).

${ }^{2}$ See Link and Scott (2005).
} 
measures the wavelength of light and sellers of equipment that is calibrated to perform various functions in high-speed fiber-optic communications will be able to convey to their customers that the equipment will perform as it should and be compatible with other manufacturers' equipment or communications services.

With such standards, a key issue confronting a company is the concern that other companies could capture its intellectual property (IP) through the process of sharing information needed to develop and maintain a standard. A public laboratory, such as the National Institute of Standards and Technology (NIST), in addition to serving as a repository of standards to which measurements are traced, could serve as an honest broker to facilitate the necessary coordination in a way that protects companies' IP and keeps the playing field level for future competition. ${ }^{3}$ Introducing standards on the one hand can make the proprietary products of a company more valuable and then, in the abstract, strengthen the IP protection-make IP have more value. On the other hand, the standards may be expected to allow more companies to be competing with their proprietary products, and that can reduce the value of the IP of an individual firm and hence, in the abstract, weaken IP protection. Together, our survey and our model enable us to describe the effectiveness of IP for innovative investments when measurement standards enabled by public laboratories are present and when they are not, and when product standards enabled by standard setting organizations and industry associations are present and when they are not. Our model allows us to incorporate the differences in the scenarios and predict the differences in results for innovative investment and the value it creates.

In addition and related to the firms' appropriability concerns, there may be antitrust issues. In trying to avoid appropriability problems or simply as a part of a standards negotiation, there is the antitrust concern about possible collusion that might lessen desirable competition. In their discussion of networks supporting invention and innovation, Powell and Giannella (2010, p. 579) list technology standards among knowledge-sharing practices that, in addition to being important for the efficiency of technological advance, have at times "dampened competition." Moreover, antitrust is concerned that such standards might disadvantage entrants and entrench incumbents. Such concerns are grounded in the important role that standards play in the evolution of high-technology industries - a role highlighted in Greenstein's (2010) analysis of the evolution of the computer and internet markets. Our approach can address such concerns because, having used industry responses to parameterize in a particular standards case our model of the economics of standards, we can simulate the effects of the standards on market equilibria.

\footnotetext{
${ }^{3}$ See Leyden and Link (1999).
} 
Section II explains our theoretical model. Section III calibrates and simulates the model first for a case study of a hypothetical research project representative of the respondent's area of research-for a large, diversified, firm among the world's leading research firms - that uses measurement standards traceable to a public, national laboratory and international standards and also works with product standards and standard setting organizations (SSOs) and industry associations. Section IV summarizes the effects on innovative investment and performance of the measurement standards and the product standards. Section V discusses the multiple effects on R\&D incentives as intellectual property (IP) protection strengthens or weakens because of the use of standards, and it then uses the responses of our industrial respondents to answer the question of how the opposing effects from changes in IP protection on balance affect innovative investments. Section VI provides our conclusions.

\section{The Model}

Our formal model develops the model in Scott (2009) in appropriate ways to allow the simulation of the model with information gathered from respondents in industry.

At the center of our model is an index $x$ of the relative quality of a company's technology (relative to the technology of its competition in the post-innovation market). The index is normalized so that $x=100$ corresponds to a situation where the quality of the respondent company's technology is equal to that of its most successful rival. Uncertainty of the technical success of both the respondent's and rivals' research efforts is reflected by the distribution over values of $x$.

The probability density function $f(x)$ depends on the respondent's R\&D effort $R_{i}$ and the research effort of rivals, denoted by $R_{-i}$. More research effort for a firm will shift its distribution rightward over higher values for $x$; more research effort by the firm's rivals will shift its distribution leftward over lower values for $x$.

In the post-innovation market, the higher the responding firm's relative quality, the more competitive it is and the higher the value-the present value of the stream of future profits in the post-innovation market- $V(x)$. We denote the present expected value of profits, which is $\int V(x) f\left(x ; R_{i}\right) d x$, by $G\left(R_{i}\right)$.

The firm chooses its research effort to maximize expected net present value-the present expected value of profits in the post-innovation market net of the cost of research effort, $w R_{i}$ (where $w$ is the unit cost of research effort ${ }^{4}$ ):

\footnotetext{
${ }^{4}$ In a theory setting, $w$ could be normalized at 1 , effectively omitting it from the model, as it is in Scott (2009). When using survey data to calibrate the model, $w$ is used to reconcile two
} 


$$
\max _{R_{i}}\left\{G\left(R_{i}\right)-w R_{i} \equiv \int V(x) f\left(x ; R_{i}\right) d x-w R_{i}\right\}
$$

Net present value is maximized when the marginal cost of $R \& D$ equals the marginal expected value: $w=d G / d R_{i}$.

This first-order condition is depicted in Figure 1 by the conventional diagram showing the iso-profit line tangent to the expected value function (analogous to the production function with the price of output normalized at 1) at the optimal level of R\&D effort:

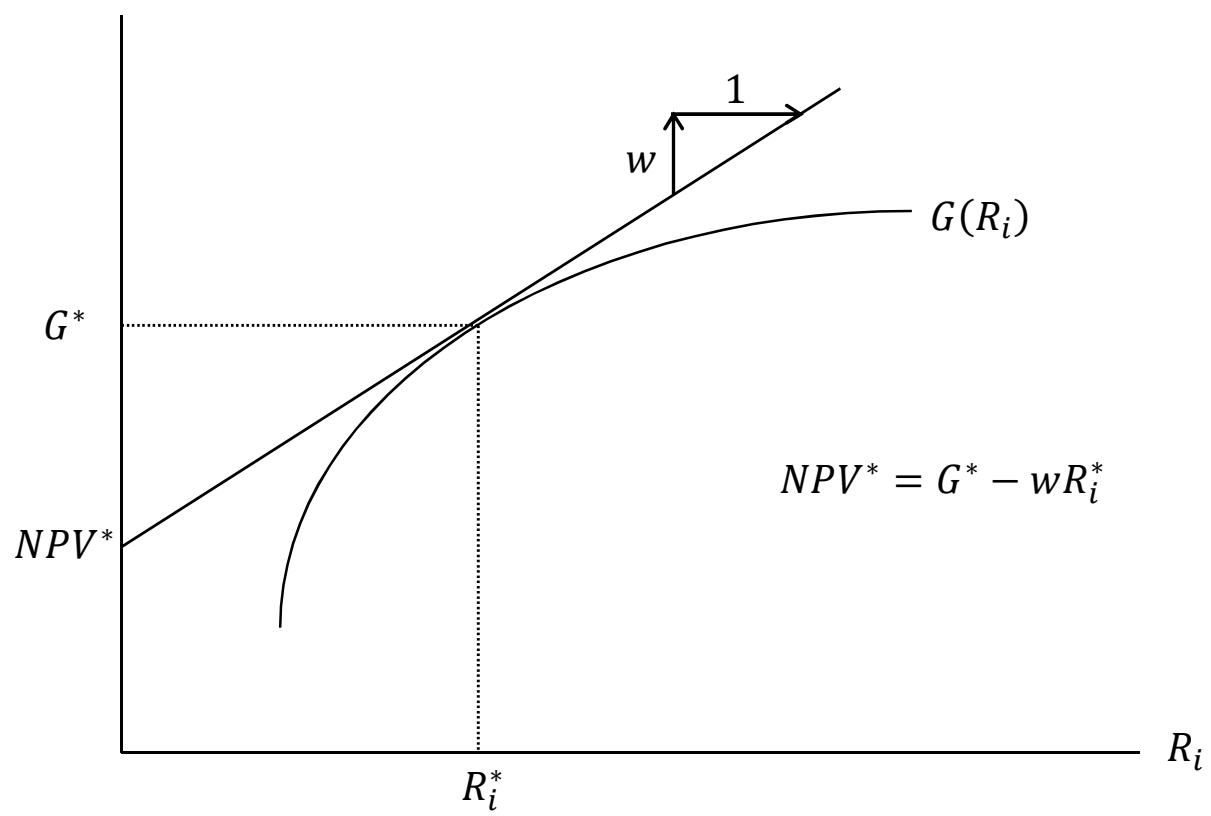

Figure 1. The optimal level of $\mathrm{R} \& D$ effort, $R_{i}^{*}$, is at the point of tangency of the isoprofit line and the expected value function.

In our case studies we calibrate our model using survey data and then use the calibrated model to describe the R\&D impacts of standards in innovative industries.

\section{Calibrating the Model with Survey Data}

Our survey begins by asking the responding firm for a description of the research being done and the standards that are used-standards for the attributes of products and services as well as standards for measurement. ${ }^{5}$ In the case study that we will present in detail to illustrate and explain our approach, the respondent, a senior R\&D manager and researcher with one of the world's preeminent research-intensive firms reports:

normalizations — of R\&D effort and the value expected in the post-innovation market - that are necessary to avoid questions about dollar figures. The details can be found in Appendix A.

${ }^{5}$ Our survey is provided in Appendix B. 
[The company] works in a huge variety of industrial research areas. The following answers to the survey are based on my small portion of [the company's] R\&D. My area of industrial research is related to the supply of new and innovative materials for the manufacture of printed wiring boards. This includes flexible copper clad laminate substrates, coverlay and bondply materials, photoimageing materials, and high performance insulating films.

The respondent explains the technology standards most relevant to the company's research as follows.

Technology standards that are most relevant to our research efforts are developed by industry associations such as IPC Association Connecting Electronic Industries, SMTA (Surface Mount Technology Association), IEEE and others related to electronics manufacturing. These standards cover a variety of areas including printed wiring board materials, printed wiring board manufacturing, assembly and quality.

The company uses measurement standards entailed in high frequency signal test methods for printed wiring boards and the standards used to calibrate precision instruments. The firm is engaged in creating new and improved photoimageable photoresists for creating printed wiring board circuitry, new and improved flexible laminates for the printed wiring board industry, and new and improved polyimide films. The measurement standards in this example include standards embodied in infrastructure technologies developed through the interactive work combining efforts of industry and federal laboratories, specifically at the National Institute of Standards and Technology (NIST). The respondent reports that for its research investments it participates in industry associations such as IPC-Association Connecting Electronic Industries-where its researchers can network with NIST personnel, and it uses publicly available highfrequency signal test methods for printed wiring boards and measurement standards to which test equipment may be calibrated with the measurements traceable to NIST.

We calibrate the model by asking the respondent to consider a hypothetical typical R\&D project in the area of industrial research as just described and to estimate (1) the expected value of $x$ and (2) the probability of $x$ being at least 25 percent greater than expected, (3) the expected value of $x$ if research effort were to vary up or down, and (4) the relative differences in present expected value that would result from different values for $x$. We assume that $f(x)$ is normal and that its mean has a simple functional relationship to $R_{i}$, namely $\int x f\left(x ; R_{i}\right) d x=c \log \left(R_{i}\right)+d$, where the parameters $c$ and $d$ are chosen to fit the responses to (3). ${ }^{6}$ The value $V(x)$ associated with equaling the quality of the state-ofthe-art technology is normalized at 100; i.e., $V(100)=100$, and the functional form of $V(x)$ is assumed to be $a(\log (x)-\log (100))+100$, with the parameter $a$ chosen to fit

\footnotetext{
${ }^{6}$ Throughout, we use log to denote the natural logarithm, sometimes denoted $\ln$.
} 
the responses to (4). Finally, $\mathrm{R} \& \mathrm{D}$ effort is normalized so that $R_{i}=100$ corresponds to the level of effort actually chosen by the respondent.

For this respondent, we have $\int x f\left(x ; R_{i}\right) d x=59.6 \log \left(R_{i}\right)-158$ with the standard deviation of the distribution at 17.4 percent of its mean, and $V(x)=48.4 \log (x)-123$. From these functions, $\int V(x) f\left(x ; R_{i}\right) d x$ and its slope can be computed numerically for any value of $R_{i}$. In this particular case, the slope at $R_{i}=100$ is found to be 0.226 . Therefore, profit-maximization requires that $w=0.226$. This gives us the value for $w$ that reconciles the normalizations of $V(100)$ and $R_{i}$, which will remain constant as the parameters $a$ and $d$ vary. $^{7}$ Moreover, present expected value in the post-innovation market can now be expressed as a multiple of research expenditure, a figure that typically is available or can be reasonably estimated. In this example, the net present value for the hypothetical project, $G^{*}-w R_{i}^{*}$, is 3.7 times the present value of the R\&D costs, $w R_{i}^{*}$. Since $G$ is some fraction of the total expected social value, including spillovers, generated by the firm's R\&D effort, it is possible to express that social value also in dollars.

\section{The Importance of Public Support and of Standards Setting Organizations}

With a sufficiently large sample of firms, in industries with different market structures and belonging to different standards-setting organizations, there is much useful insight to be gleaned from the preceding information alone. However, we want to address the impacts on R\&D investment and performance of both public infrastructure technology for measurement standards and standards setting organizations (SSOs) and other industry associations involved with standards. Our survey in the field goes on to ask about hypothetical, counterfactual situations in which first the government labs and the infrastructure technology they provide are absent from the standards-setting activities. We then ask about the counterfactual situation where there is an absence of SSOs and other industry associations supporting standards activities. The firm estimates how $f(x ; R)$ and $V(x)$ could be expected to change in these counterfactual cases.

The First Counterfactual: The Absence of Standards Support from Public Laboratories. For the first counterfactual, we first ask the respondent whether NIST or other public labs have played a significant role in the development of technology standards most relevant to the company's research efforts in the area of research relevant for the hypothetical project being discussed. The respondent for the particular case study being described here reports:

\footnotetext{
${ }^{7}$ See Appendix A for details.

${ }^{8}$ Our results are not very sensitive to the assumption of normal distribution with the standard deviation a constant fraction of the mean. We reach very similar results by ignoring the distribution altogether, supposing that the company maximizes not $G\left(R_{i}\right)$ $w R_{i}=\int V(x) f\left(x ; R_{i}\right) d x-w R_{i}$, but instead $V(E(x))-w R_{i}$.
} 
Volunteers from NIST and other labs . . . participate as either leaders or participants on many of the standards development committees and task groups. As such, they bring discipline to these efforts by ensuring that any round robin testing is done in a quality manner as well as helping to ensure that the standards that are developed are done in a manner that uses science as a basis.

We then ask the respondent:

. . . to imagine a counterfactual situation without the involvement of NIST or other public labs in the standard setting process. Try to imagine this situation, given the best response of your company, rival companies, and relevant industry organizations in the absence of this public support.

In our example, the respondent estimated that in the counterfactual case the R\&D effort needed to achieve a given (expected) quality index would be 25 percent higher: $\int x f\left(x ; R_{i}\right) d x=59.6 \log \left(R_{i} / 1.25\right)-158=59.6 \log \left(R_{i}\right)-[59.6 \log (1.25)+158]$.

This implies a leftward shift in the distribution and a rightward shift in the production function. Facing a more difficult R\&D problem, the optimal level of R\&D effort increases and net present value falls, as depicted in Figure 2:

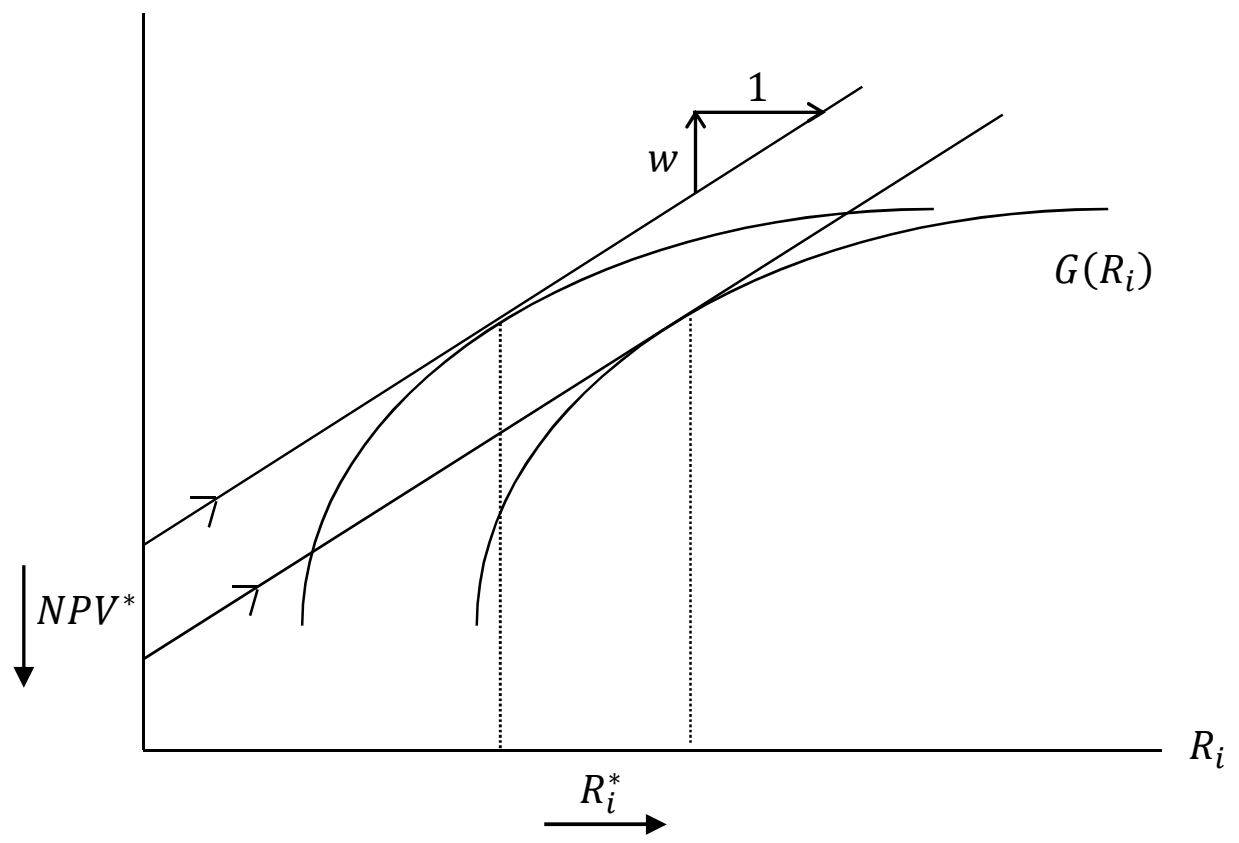

Figure 2. The effect of an unfavorable distribution shift on optimal R\&D effort and net-present value.

The effect on the relation between $\mathrm{R} \& \mathrm{D}$ and quality is not the entire story. For our illustrative example, the respondent reports that the value in the post-innovation market would also be 10 percent lower in counterfactual case because of what the standards are 
doing for production and commercialization. Thus, $V(x)=(0.90)[48.4 \log (x)-123]$. This has the effect of reducing optimal R\&D effort and reducing NPV. If the distribution shifting effect and the value-reducing effect on optimal R\&D effort offset exactly, then these NPV-reducing effects reinforce each other, and as depicted in Figure 3, NPV is reduced while R\&D investment stays the same. However, in the present case, the valuereducing effect more than offsets the distribution-shifting effect, and the amount of R\&D investment in the counterfactual case for the hypothetical project falls to 64.4 percent of the effort when the public support for standards activities is present.

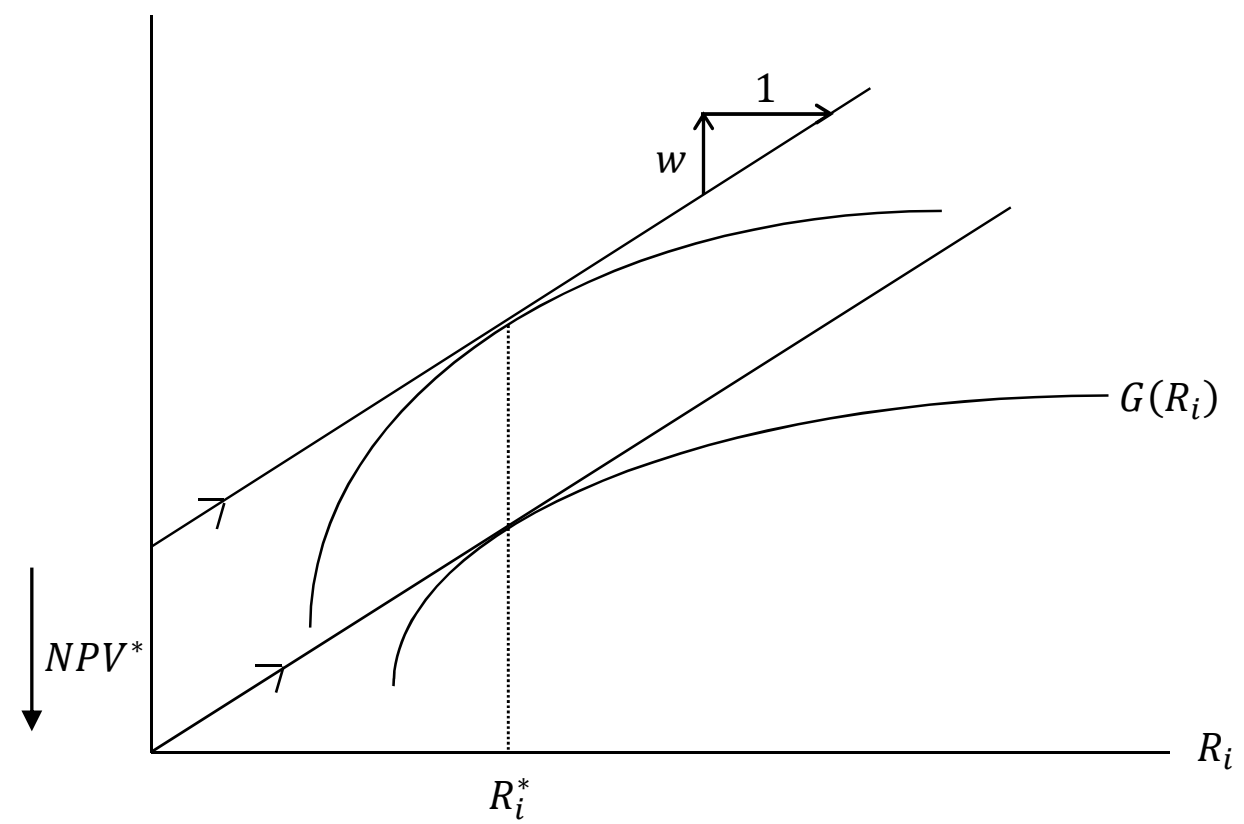

Figure 3. The combined distribution-shifting and value-shifting effects of taking away the government laboratory's role in standards-setting.

We described above for the benchmark case how to turn $G$ into a dollar amount, and we can do the same thing in the counterfactual case-using the model and the answers to a few questions, we can estimate that the number is a certain percent of actual $R \& D$ expenditure, and then we can look at what the firm spends on R\&D in a typical year. As in the benchmark case, we would want to apply an appropriate multiplier to the value the firm captures in order to get the social value, including spillovers. The difference between the social value in each case provides an estimate of the social value that is attributable to the government lab's role in standards-setting-looking just at this one firm and any spillovers from this firm's activity. ${ }^{9}$

\footnotetext{
${ }^{9}$ When there is a difference, as there is in the present case being used for illustration, in private $R \& D$ effort between the actual and counterfactual cases, either because of additional effort in the counterfactual case to replicate the lab's contribution or because of complementarities between
} 
The Second Counterfactual: The Absence of Standards Support from SSOs and Industry Associations. For the second counterfactual, we first ask the respondent whether SSOs or industry associations played a significant role in the development of technology standards most relevant to the company's research efforts being discussed in this case. The respondent for the particular case study being described here answers yes and reports:

The standards developed by SSOs create a framework within which we do our $R \& D$ in that many of the needed physical properties are identified and the range of acceptable levels is also specified. Without this information, it would be much more difficult to develop products that would be useful to a wide range of companies. This is because the effort of obtaining "Voice of the Customer" from each customer would be very difficult. In addition, the standards help to provide general agreement on how the physical properties should be measured, thus avoiding miscommunication between the developer ... and the customer.

We then ask the respondent:

. . . to imagine a counterfactual situation without the involvement of SSOs and industry associations in the standard setting process. Try to imagine this situation, given the best response of your company and rival companies in the absence SSOs and industry associations.

In this counterfactual situation without SSOs and industry associations, the respondent reports that the $R \& D$ effort required to achieve a given $R \& D$ quality index would increase by $50 \%$. Moreover, the value of $R \& D$ outcomes would decrease by $30 \%$ in the absence of the SSOs and industry associations.

In this counterfactual, without the SSOs and industry associations to support the standards work, the NPV for our respondent's hypothetical research project falls to about half of its value given the SSOs and industry associations and the net result of the distribution-shifting and value-shifting effects on R\&D investment is to decrease the investment to $93 \%$ of what it would be with the SSOs and industry associations.

Sample Averages: Comparisons of Impacts for the Counterfactual Scenarios. We hope to obtain the cooperation of one of more SSOs or industry associations for a large sample study of their members' R\&D managers; Chiao et al. (2007) provide a list of such organizations. For the present paper in which we explain our methodology, we have worked with a small set of respondents, identified during earlier evaluation projects

public and private research crowding-in additional private investment in the actual case, then that would also enter into the calculation. For example, additional private investment in the actual case would need to be subtracted from the additional value attributable to the public lab. 
(some of those are reviewed in Link and Scott (2013)), who responded to our request for their opinions.

In the following tables, we provide averages for the key results for all of the respondents used for our case studies. Our other respondents included companies working with standards in a variety of ways. Included were companies providing (1) tests to new standards-for compliance to energy efficiency, electrical safety and interoperability standards-for electronic and electrical products for telecommunications, home entertainment, information technology, and power supply markets; (2) computer applications in image display techniques and display device calibration for medical imaging, working with display metrology standards for the measurement of luminance and chromaticity and calibration of luminance and color measuring devices, standards for image storage and transmission; (3) work with standards in the same areas described by the respondent used to provide the example illustrating our methodology. The respondents report that they work with standards written by committees that include industry, laboratory test facilities, government representatives, industry and trade associations, standards setting organizations (SSOs), and other interested parties. They work with national laboratories such as NIST and with the support of SSOs and trade associations and private labs.

For each scenario, we asked each respondent for their approximation of the proportion of their typical research project's total value that would not be captured by their company but would spill over to other firms (as producer surplus) and customers (as consumer surplus). Such approximations are of course especially difficult to make, and so for our summary calculations about the social value of the hypothetical respondents, we use the average of the approximations for the spillover rates provided by the respondents.

Table 1 provides the averages of key metrics for the respondents used for our case studies. We worked with five responses about the actual scenario for a typical research project.

Table 1. Means for Key Metrics for the Research Projects in the Actual Situation, $n$ $=5$.

Variable

Mean

Standard Deviation

Private Value/Cost,

10.7

$\mathrm{G}^{*} /(\mathrm{wR} *)$

Private Net Present Value/Cost, $\quad 9.68$

$\left(\mathrm{G}^{*}-\mathrm{wR}^{*}\right) /(\mathrm{wR} *)$

(Total Social Value)/(Private Cost) 18.2

20.8 
In four of the five cases summarized in Table 1, the respondent also provided the description of the counterfactual scenario without the support of public laboratories. Table 2 provides the averages for the percentage changes in the key metrics for the counterfactual case where the companies do not have the public laboratory support for their use of standards. R\&D investment falls by 11 percent, the private benefit-to-cost ratio falls by 17 percent, and the social benefit-to-private-cost ratio falls by 26 percent.

Table 2. Proportional Changes in Metrics for the Counterfactual without Public Lab Support, $n=4$.

\begin{tabular}{|c|c|c|}
\hline Variable & Mean & Standard Deviation \\
\hline$\overline{\Delta \mathrm{G}^{*} /\left(\mathrm{G}^{*}{ }_{\text {initial }}\right)}$ & -0.25 & 0.19 \\
\hline$\Delta\left(\mathrm{wR}^{*}\right) /\left(\mathrm{wR}^{*}{ }_{\text {initial }}\right)$ & -0.11 & 0.18 \\
\hline$\Delta\left(\mathrm{G}^{*} /(\mathrm{wR} *)\right) /\left(\mathrm{G}^{*} /(\mathrm{wR} *)\right)_{\text {initial }}$ & -0.17 & 0.097 \\
\hline$\Delta\left[\left(\mathrm{G}^{*}-\mathrm{wR}^{*}\right) / \mathrm{w} \mathrm{R}^{*}\right] /\left[\left(\mathrm{G}^{*}-\mathrm{wR}^{*}\right) / \mathrm{w} \mathrm{R}^{*}\right]_{\text {initial }}$ & -0.30 & 0.35 \\
\hline$\Delta\left(V_{s o c i a l} / \mathrm{wR}^{*}\right) /\left(\mathrm{V}_{\text {social}} / \mathrm{wR}^{*}\right)_{\text {initial }}$ & -0.26 & 0.12 \\
\hline
\end{tabular}

In three of the five cases summarized in Table 1, the respondent provided the information about the counterfactual scenario without the support of SSOs or industry associations. Table 3 provides the averages for the percentage changes in the key metrics for the counterfactual case where the companies do not have the support of SSOs and industry organizations. In that counterfactual, $R \& D$ investment falls by 18 percent, the private benefit-to-cost ratio falls by 24 percent, and the social benefit-to-private-cost ratio falls by 38 percent.

Table 3. Proportional Changes in Metrics for the Counterfactual without SSO and Industry Association Support, n = 3 .

\begin{tabular}{|c|c|c|}
\hline Variable & Mean & Standard Deviation \\
\hline$\overline{\Delta \mathrm{G}^{*} /\left(\mathrm{G}^{*}{ }_{\text {initial }}\right)}$ & -0.38 & 0.16 \\
\hline$\Delta\left(\mathrm{wR}^{*}\right) /\left(\mathrm{wR}^{*}{ }_{\text {initial }}\right)$ & -0.18 & 0.16 \\
\hline$\Delta\left(\mathrm{G}^{*} /\left(\mathrm{w} \mathrm{R}^{*}\right)\right) /\left(\mathrm{G}^{*} /\left(\mathrm{w} \mathrm{R}^{*}\right)\right)_{\text {initial }}$ & -0.24 & 0.11 \\
\hline$\Delta\left[\left(\mathrm{G}^{*}-\mathrm{wR}^{*}\right) / \mathrm{wR} *\right] /\left[\left(\mathrm{G}^{*}-\mathrm{wR}^{*}\right) / \mathrm{wR}^{*}\right]_{\text {initial }}$ & -0.28 & 0.16 \\
\hline$\Delta\left(\mathrm{Vsocial} / \mathrm{wR}^{*}\right) /\left(\mathrm{V}_{\text {social }} / \mathrm{wR}^{*}\right)_{\text {initial }}$ & -0.38 & 0.095 \\
\hline
\end{tabular}




\section{Effects of Stronger or Weaker Intellectual Property (IP) Protection}

There are multiple effects on $R \& D$ incentives as intellectual property protection strengthens or weakens because of the use of standards. One effect can be through a change in the proportion of the value of innovative investment that is captured by rivals. We have that effect for both the public labs and the SSOs scenarios by asking our respondents about the proportion in fact and then how the proportion changes in the counterfactual situations. But while each firm fails to capture some of the value that it creates, for that very reason each will benefit from the value created by its rivals research projects. Comparing our counterfactual cases with the actual situation, we can observe that the net effects of the spillovers received and the spillovers lost.

Beyond the effects from the proportion of the total value of a firm's research project that the firm appropriates, when we introduce standards (whether using the public labs or the SSOs and industry associations), we quite generally introduce effects on the value of relative performance and on the probability distribution over relative performance. Those effects can, perhaps somewhat subtly, be attributed to changes in intellectual property protection. Such changes comprise a more complicated set of relations than simply the strength of a patent measured in various ways (such as the length of legal patent protection, the length of time before rivals can invent around the patent, the increase in an innovation's profit margin because of the patent, etc.) but it is in fact perhaps equally an important story about IP protection. Introducing standards on the one hand can make the proprietary products of a company more valuable and then in the abstract strengthen the IP protection-make it have more value. On the other hand, the standards may be expected to allow more companies to be competing with their proprietary products, and that can reduce the value of IP and hence in the abstract weaken IP protection. We expect that standards both strengthen and weaken IP protection, and our method allows us to sort out the various effects and see on balance what is the overall effect on innovative investment and performance.

\section{Conclusions}

From our model and our calibration of it using case studies from industry, we find that the support for standards provided by public laboratories and SSOs and industry associations have a large impact on the private and social value of industrial research. The finding is consistent with what our respondents say in their prose descriptions of the importance of the support they receive from public laboratories and SSOs and industry associations. One respondent wrote: "Without efforts of [the SSOs and industry associations] with NIST support, there would be total anarchy and chaos. SSOs level the playing field for researchers large and small." Another respondent stated that without support for standards provided by SSOs and industry associations, 
Manufacturers will try to separate themselves from others by implementing non-standardized processes and then let the market choose the winner. It is hard to learn if you are not part of a group that has a common goal.

Our findings are also consistent with our respondents' views that there would be a dramatic decline in the quality of the products and services they create without the support of standards supported by public laboratories and by SSOs and industry associations. Table 4 summarizes the respondents statements about the decline in quality that would result without such support for standards and their use.

Table 4. The Loss in Quality in the Absence of Support for Standards.

As a rough estimate, in the counterfactual case without public support for technology standards, the expected quality of the state-of-the-art would be percent of the expected state-of-the-art quality with the public support. mean standard deviation

4 77.5

19.9

As a rough estimate, in the counterfactual case without SSOs and industry associations, the expected quality of the state-of-the-art would be percent of the expected stateof-the-art quality with SSOs and industry associations.

n mean standard deviation

$3 \quad 56.7 \quad 11.5$

Having developed our methodology and having applied it in a small sample of case studies, we are now developing large samples of respondents across many different industries, different types of research, and different types of firms. In future research, we hope to apply our methodology to the large samples, report the findings, and provide econometric analysis of the large sample findings. 


\section{References}

Chiao, Benjamin, Lerner, Josh, and Tirole, Jean, "The Rules of Standard-Setting Organizations: An Empirical Analysis," The RAND Journal of Economics, Volume 38, Number 4 (Winter 2007), pp. 905-930.

Greenstein, Shane, "Innovative Conduct in Computing and Internet Markets," Chapter 11 of Economics of Innovation: Handbook on the Economics of Innovation, vol. 1, edited by Bronwyn H. Hall and Nathan Rosenberg, in Handbooks in Economics, Series Editors Kenneth J. Arrow and Michael D. Intriligator (Elsevier, 2010), pp. 477-537.

Leyden, Dennis P., and Link, Albert N., "Federal Laboratories as Research Partners," International Journal of Industrial Organization, Vol. 17, No. 4 (May 1999), pp. 572-592.

Link, Albert N., and Scott, John T., "Evaluating Public Sector R\&D Programs: The Advanced Technology Program's Investment in Wavelength References for Optical Fiber Communications," The Journal of Technology Transfer, Vol. 30, Nos. 1-2 (January 2005), pp. 241-251.

Link, Albert N., and Scott, John T., "The Theory and Practice of Public-Sector R\&D Economic Impact Analysis," Chapter 2 of Handbook on the Theory and Practice of Program Evaluation, edited by Albert N. Link and Nicholas S. Vonortas (Edward Elgar, 2013), pp. 15-55.

Link, Albert N., and Tassey, Gregory, Strategies for Technology-Based Competition: Meeting the New Global Challenge (Lexington, Mass., D.C. Heath, 1987).

Powell, Walter W., and Giannella, Eric, "Collective Invention and Inventor Networks," Chapter 13 of Economics of Innovation: Handbook on the Economics of Innovation, vol. 1, edited by Bronwyn H. Hall and Nathan Rosenberg, in Handbooks in Economics, Series Editors Kenneth J. Arrow and Michael D. Intriligator (Elsevier, 2010), pp. 575-605.

Scott, John T., "Competition in Research and Development: A Theory for Contradictory Predictions," Review of Industrial Organization, Volume 34, Number 2 (March 2009), pp. 153-171.

Tassey, Gregory, The Economics of R\&D Policy (Westport, CT: Quorum Books, 1997). 


\section{APPENDIX A}

The two lemmas and two theorems that follow establish the validity of the normalizations of the mean-index function and value function and the use of $w$ to reconcile the two normalizations. The assumed functional forms are simple of course. We assume that these simple functional forms can offer reasonable descriptions of the relationships between (1) expected quality and research expenditure and (2) value and quality when expenditures and value are expressed in dollars. We then show that the normalizations

describe identical relationships (Theorem 1) and

$\square$ remain valid as the functions change to describe the counterfactual scenario (Theorem 2).

Lemma 1: If $\hat{V}(x)=\hat{a} \log (x)+\hat{b}$ is the present dollar value of the relative quality outcome indexed by $x$, then there exists a function $V(x)=a \log (x)+b$, with $a=100 \hat{a} /(\hat{a} \log (100)+\hat{b})$ and $b=100 \hat{b} /(\hat{a} \log (100)+\hat{b})$, such that

(i) $V(100)=100$ and

(ii) $V\left(x^{\prime}\right) / V(x)=\hat{V}\left(x^{\prime}\right) / \widehat{V}(x)$ for any two index values $x$ and $x^{\prime}$.

Proof of (i): Let $V(x)=a \log (x)+b$, with $a=\frac{100 \hat{a}}{\hat{a} \log (100)+\hat{b}}$ and $b=\frac{100 \hat{b}}{\hat{a} \log (100)+\hat{b}}$

Then $V(100)=\left(\frac{100 \hat{a}}{\hat{a} \log (100)+\hat{b}}\right) \log (100)+\frac{100 \hat{b}}{\hat{a} \log (100)+\hat{b}}$

$$
\begin{gathered}
=100\left(\left(\frac{\hat{a}}{\hat{a} \log (100)+\hat{b}}\right) \log (100)+\frac{\hat{b}}{\hat{a} \log (100)+\hat{b}}\right) \\
=100\left(\frac{\hat{a} \log (100)+\hat{b}}{\hat{a} \log (100)+\hat{b}}\right)=100
\end{gathered}
$$

Proof of (ii): Let $V(x)=a \log (x)+b$, with $a=\frac{100 \hat{a}}{\hat{a} \log (100)+\hat{b}}$ and $b=\frac{100 \hat{b}}{\hat{a} \log (100)+\hat{b}}$

Then

$$
\begin{gathered}
\frac{V\left(x^{\prime}\right)}{V(x)}=\frac{\left(\frac{100 \hat{a}}{\hat{a} \log (100)+\hat{b}}\right) \log \left(x^{\prime}\right)+\frac{100 \hat{b}}{\hat{a} \log (100)+\hat{b}}}{\left(\frac{100 \hat{a}}{\hat{a} \log (100)+\hat{b}}\right) \log (x)+\frac{100 \hat{b}}{\hat{a} \log (100)+\hat{b}}} \\
=\left(\frac{\hat{a} \log \left(x^{\prime}\right)+\hat{b}}{\hat{a} \log (x)+\hat{b}}\right)=\frac{\hat{V}\left(x^{\prime}\right)}{\widehat{V}(x)}
\end{gathered}
$$


Corollary: If there exists a function $V(x)=a \log (x)+b$, with $b=100-a \log (100)$, such that $V\left(x^{\prime}\right) / V(x)=\widehat{V}\left(x^{\prime}\right) / \widehat{V}(x)$ when $\widehat{V}\left(x^{\prime}\right)$ and $\widehat{V}(x)$ are the present dollar values of the relative quality outcomes indexed by any $x^{\prime}$ and $x$, then $\widehat{V}(x)=$ $\hat{a} \log (x)+\hat{b}$ where $\hat{a}=(\hat{V}(100) / 100) a$ and $\hat{b}=(\hat{V}(100) / 100) b$.

Lemma 2: If $E(x)=\hat{\mu}(R)=\hat{c} \log (R)+\hat{d}$ is the expected value of the relative quality outcome index $x$ when the present dollar value of research outlays is $R$, then there exists a function $\mu(R)=c \log (R)+d$, with $c=\hat{c}$ and $d=\hat{\mu}(\tilde{R})-\hat{c} \log (100)$, such that

$$
\begin{aligned}
& \text { (i) } \mu(100)=\hat{\mu}(\tilde{R}) \\
& \text { and } \quad \text { (ii) } \mu\left(100\left(\frac{R^{\prime}}{\tilde{R}}\right)\right)=\hat{\mu}\left(R^{\prime}\right)
\end{aligned}
$$

Proof: Let $\mu(R)=c \log (R)+d$, with $c=\hat{c}$ and $d=\hat{\mu}(\tilde{R})-\hat{c} \log (100)$,

$$
\begin{aligned}
& \begin{array}{l}
\text { Then (i) } \mu(100)=\hat{c} \log (100)+\hat{\mu}(\tilde{R})-\hat{c} \log (100) \\
=\hat{\mu}(\tilde{R}) \\
\text { and (ii) } \mu\left(100\left(\frac{R^{\prime}}{\tilde{R}}\right)\right) \\
=\hat{c} \log \left(100\left(\frac{R^{\prime}}{\tilde{R}}\right)\right)+\hat{\mu}(\tilde{R})-\hat{c} \log (100) \\
=\hat{c} \log (100)+\hat{c} \log \left(R^{\prime}\right)-\hat{c} \log (\tilde{R})+\hat{c} \log (\tilde{R})+\hat{d}-\hat{c} \log (100) \\
=\hat{c} \log \left(R^{\prime}\right)+\hat{d}=\hat{\mu}\left(R^{\prime}\right) \quad
\end{array}
\end{aligned}
$$


Theorem 1: Let $\hat{V}(x)=\hat{a} \log (x)+\hat{b}$ be the present dollar value of the relative quality outcome indexed by $x$, and let $E(x)=\hat{\mu}(R)=\hat{c} \log (R)+\hat{d}$ be the expected value of $x$ when the present dollar value of research outlays is $R$. Suppose also that the probability density function for $x$ is $f(x ; R)=f(x ; \hat{\mu}(R))$ - that is, suppose that the density function depends on $R$ through a single parameter $\mu$.

Let $V(x)$ be defined as in Lemma 1 , and let $\mu(R)$ be defined as in Lemma 2 with $\tilde{R}$ the optimal research outlay, so that $\tilde{R}$ satisfies the first-order condition

$$
\frac{d \hat{\mu}}{d R} \int \hat{V}(x) \frac{d f}{d \mu} d x=\frac{\hat{c}}{R} \int \hat{V}(x) \frac{d f}{d \mu} d x=1
$$

Then $R=100$ satisfies the analogous first-order condition in normalized units for $V(x)$ and $R$, namely

$$
\frac{d \mu}{d R} \int V(x) \frac{d f}{d \mu} d x=\frac{c}{R} \int V(x) \frac{d f}{d \mu} d x=w=\frac{\tilde{R}}{\hat{a} \log (100)+\hat{b}}
$$

Proof:

Starting from the first-order condition with normalized units, satisfied when $R=100$, we work backwards to obtain the first-order condition in dollars, satisfied when $R=\tilde{R}$.)

$$
\begin{gathered}
\frac{c}{100} \int V(x) \frac{d f}{d \mu} d x=\frac{\tilde{R}}{\hat{a} \log (100)+\hat{b}} \\
\Leftrightarrow \frac{\hat{c}}{100}\left(\frac{100}{\hat{a} \log (100)+\hat{b}}\right) \int \hat{V}(x) \frac{d f}{d \mu} d x=\frac{\tilde{R}}{\hat{a} \log (100)+\hat{b}} \\
\Leftrightarrow \hat{c} \int \hat{V}(x) \frac{d f}{d \mu} d x=\tilde{R} \\
\Leftrightarrow \hat{c} \frac{\hat{c}}{\tilde{R}} \int \hat{V}(x) \frac{d f}{d \mu} d x=1
\end{gathered}
$$


Theorem 2: Let $\hat{V}(x)$ and $\hat{\mu}(R)$ from Theorem 1 be disturbed such that the value and expectation of $x$ are now described by $\hat{\dot{V}}(x)=m \hat{V}(x)=m \hat{a} \log (x)+m \hat{b}$ and $E(x)=\hat{\dot{\mu}}(R)=\hat{\mu}\left(\frac{R}{r}\right)=\hat{c} \log \left(\frac{R}{r}\right)+\hat{d}$. (In words, technology changes so that the value of any given $x$ increases by $100(m-1)$ percent and the research outlay required to achieve any given $x$ in expectation increases by $100(r-1)$ percent.)

Then, in order to accurately reflect this disturbance when working in the normalized units as defined in Theorem 1, we have only to redefine $V(x)$ and $\mu(R)$ as follows: $\dot{V}(x)=m V(x)=m a \log (x)+m b$ and $\dot{\mu}(R)=\mu\left(\frac{R}{r}\right)=c \log \left(\frac{R}{r}\right)+d$.

In particular, the normalized unit cost of research remains

$$
w=\frac{\tilde{R}}{\hat{a} \log (100)+\hat{b}}
$$

Proof: In dollars, the first-order condition will be satisfied for $R$ such that

$$
\frac{\hat{c}}{R} \int \hat{V}(x) \frac{d f}{d \mu} d x=\frac{m \hat{c}}{R} \int \hat{V}(x) \frac{d f}{d \mu} d x=1
$$

Let us call the optimal research outlay $R^{\$}=m \hat{c} \int \hat{V}(x) \frac{d f}{d \mu} d x$.

In normalized units, the first-order condition will be satisfied for $R$ such that

$$
\begin{gathered}
\frac{c}{R} \int \dot{V}(x) \frac{d f}{d \mu} d x=w=\frac{\tilde{R}}{\hat{a} \log (100)+\hat{b}} \\
\Leftrightarrow \frac{\hat{c}}{R}\left(\frac{100}{\hat{a} \log (100)+\hat{b}}\right) \int \hat{\dot{V}}(x) \frac{d f}{d \mu} d x=\frac{\tilde{R}}{\hat{a} \log (100)+\hat{b}} \\
\Leftrightarrow m \hat{c}\left(\frac{100}{R}\right) \int \hat{V}(x) \frac{d f}{d \mu} d x=\tilde{R}
\end{gathered}
$$

Let us call the optimal normalized outlay $R^{*}=m \hat{c}\left(\frac{100}{\tilde{R}}\right) \int \hat{V}(x) \frac{d f}{d \mu} d x$ and notice that $R^{*}=\left(\frac{100}{\tilde{R}}\right) R^{\$}$, or $\frac{R^{*}}{100}=\frac{R^{\$}}{\tilde{R}}$, showing that the percentage change in the optimal research outlay is the same in either dollars or normalized units. 


\section{Appendix B \\ Survey on \\ Technology Standards in Innovative Industries}

John T. Scott

Professor of Economics

Dartmouth College, Department of Economics

Hanover, NH 03755

27709
Troy J. Scott

Research Economist

RTI International

Research Triangle Park, NC

The purpose of this survey is to evaluate the impact of technology standards on innovative activity. Important technology standards to be considered include standards for the attributes of products (e.g., USB ports) and services (e.g., protocols allowing exchange of data in high-speed communications networks) as well as standards for measurement (e.g., thermocouple calibration for the accurate measurement of temperature, traceable to a national or international standard).

Your participation will help in developing qualitative descriptions of the standard setting process and quantitative assessments of the impact of standards on innovative activity. We are especially interested in understanding the role of public labs, such as those of the National Institute of Standards and Technology (NIST) in the U.S., in the development of technology standards.

This is an independent academic research project (rather than a project for NIST or RTI International); the research paper generated from the results of this survey will be presented at a Research Roundtable Conference on Technology Standards and Innovation, to be hosted by the Searle Center on Law, Regulation, and Economic Growth at Northwestern University in February, 2013, and is expected to be published in an edited volume following the conference.

The information you will be asked to provide is abstract, hypothetical, and normalized. The identity of individual respondents will be kept confidential.

We deeply appreciate your taking the time to share your insights with us. Please do not hesitate to contact either of us with any questions or to provide verbal responses to the survey if that is most convenient for you. Our contact information is as follows:

John T. Scott

john.t.scott@dartmouth.edu

603.646.2941
Troy J. Scott

tjscott@uw.edu

206.550.6076 
I. Descriptive Statement of Research and Associated Standards

Please provide a brief description of the area of industrial research in which your company has most often worked:

Please provide a brief description of the technology standards most relevant to your company's research efforts. We are interested in standards for the attributes of products and services as well as standards for measurement. 
II. The following questions ask you to consider a hypothetical typical R\&D project in the area of industrial research in which your company has most often worked.

\section{Please feel free to add comments at any point.}

1. Imagine an index of the quality of the outcome for a typical $R \& D$ project. An index of 100 indicates that the quality of the outcome is equal to the quality of the best outcome among rival companies performing similar research. An index of 125 indicates that the quality of the outcome is $25 \%$ better than that of the best outcome among rival companies. An index of 80 indicates that the quality of the outcome is $20 \%$ less than the quality of the best outcome among rival companies.

Given the research efforts described in Part I, and given the anticipated R\&D effort of rival companies during the same time period, what would you expect your company's index to be, following the completion of the hypothetical R\&D project?

2. As a rough estimate, what is the probability that your company's index would turn out to be more than $25 \%$ higher than the value reported in Question 1?
Less than $5 \%$
$5 \%-10 \%$
$11 \%-20 \%$
$21 \%-40 \%$

$\%$ (other, please specify)

3. As a rough estimate, what would you expect your company's quality index to be if its R\&D effort were to decrease by 25 percent while the $R \& D$ effort of rival companies did not change?

What would you expect your company's index to be if its R\&D effort were to increase by 25 percent, while the R\&D effort of rival companies did not change?

What would you expect your company's index to be if its R\&D effort were to increase by 50 percent, while the $\mathrm{R} \& \mathrm{D}$ effort of rival companies did not change? 
What would you expect your company's index to be if its R\&D effort were to increase by 100 percent, while the R\&D effort of rival companies did not change?

4. Imagine an index of the value to your company - the present value to your company of the stream of future profits in the post-innovation market available to provide a return on the $R \& D$ investment - associated with a given index of $R \& D$ quality. Normalize this value index so that the value of equaling the quality of the best $R \& D$ outcome among rival companies is 100 (i.e., the value index is 100 when the R\&D quality index, considered above, is 100). A value index of 125 would describe a situation where the expected profit stream has a present value $25 \%$ higher than the profit stream that would be expected if your company's R\&D index was 100 .

As a rough estimate, what value index would you associate with an R\&D quality index of 110?

As a rough estimate, what value index would you associate with an R\&D quality index of $\mathbf{1 2 5}$ ?

As a rough estimate, what value index would you associate with an R\&D quality index of $\mathbf{1 5 0}$ ?

5. Typically, a company will not capture all of the value of its $R \& D$ outcomes because competition keeps prices below what end users of the technology would be willing to pay in the absence of such competition and because other companies often benefit by observing the technology and applying what they learn to their own R\&D efforts.

As a rough estimate, what percentage of the total social value of your company's $\mathrm{R} \& \mathrm{D}$ outcomes do you anticipate will be captured by other companies and end users of the technology created by your company's R\&D?
$<10 \%$
10-20\%
20-30\%
$30-40 \%$
$40-50 \%$
50-60\%
60-70\%
$70-80 \%$
$80-90 \%$
$>90 \%$ 
III. Part III of the survey asks about the role of any public labs (in the U.S., for example, NIST or other labs) in developing and maintaining the technology standards most relevant to your company's research efforts.

Again, please feel free to add comments at any point.

1. Have public labs played a significant role in the development of technology standards most relevant to your company's research efforts?

(YES/NO). If NO, please skip the next four questions. If YES, please explain briefly:

The final four questions in Part III ask you to imagine a counterfactual situation without the involvement of public labs in the standard setting process. Try to imagine this situation, given the best response of your company, rival companies, and relevant industry organizations in the absence of this public support.

2. How would the quality of the best R\&D outcome (the state-of-the-art) change?

As a rough estimate, in the counterfactual case without public support for technology standards, the expected quality of the state-of-the-art would be percent of the expected state-of-the-art quality with the public support.

(Responses less than 100 indicate a lower-quality state-of-the-art in the counterfactual case. Responses greater than 100 indicate a higher-quality stateof-the-art in the counterfactual case.) 
3. How would the level of $R \& D$ effort required to achieve a given $R \& D$ quality index (as in Part II, Questions 1 and 3) change? ${ }^{10}$

As a rough estimate, in the counterfactual case without public support for technology standards, the level of $R \& D$ effort required to achieve a given $R \& D$ quality index would be percent of the effort required to achieve the same R\&D quality index with the public support.

(Responses less than 100 indicate that less effort is required to achieve a given R\&D quality index in the counterfactual case. Responses greater than 100 indicate that more effort is required in the counterfactual case.)

4. How would the value to your company - the present value to the company of the stream of future profits in the post-innovation market available to provide a return on the $R \& D$ investment-associated with a given $R \& D$ quality index change?

As a rough estimate, in the counterfactual case without public support for technology standards, the value of a given R\&D quality index would be percent of the value of the same $R \& D$ quality index with the public support.

(Responses less than 100 indicate that a given R\&D quality index is less valuable in the counterfactual case. Responses greater than 100 indicate that a given $R \& D$ quality index is more valuable in the counterfactual case.)

5. In Part II, Question 5 asked about the percentage of the total social value of your company's R\&D that is captured by other companies and end users. In the counterfactual case without public support for technology standards, would your answer to this question change? (Yes/No).

If yes, which answer? $\%$

\footnotetext{
${ }^{10}$ Note: The effort required could go down if, for example, the anticipated state-of-the-art quality is lower in the counterfactual case. The effort required could go up if, for example, it is more costly in the counterfactual case to achieve a given outcome. In the presence of such countervailing effects, it is possible for the required level of effort to rise or to fall or to remain unchanged overall.
} 
IV. The fourth and final part of the survey asks about the role of standard setting organizations (SSOs) and/or industry associations in developing and maintaining the technology standards most relevant to your company's research efforts.

Again, please feel free to add comments at any point.

1. Have SSOs or industry associations played a significant role in the development of technology standards most relevant to your company's research efforts?

(YES/NO). If NO, please skip the next four questions. If YES, please explain briefly:

The final four questions in Part IV ask you to imagine a counterfactual situation without the involvement of SSOs and industry associations in the standard setting process. Try to imagine this situation, given the best response of your company and rival companies in the absence SSOs and industry associations.

2. How would the quality of the best R\&D outcome (the state-of-the-art) change?

As a rough estimate, in the counterfactual case without SSOs and industry associations, the expected quality of the state-of-the-art would be percent of the expected state-of-the-art quality with SSOs and industry associations.

(Responses less than 100 indicate a lower-quality state-of-the-art in the counterfactual case. Responses greater than 100 indicate a higher-quality stateof-the-art in the counterfactual case.) 
3. How would the level of $R \& D$ effort required to achieve a given $R \& D$ quality index (as in Part II, Questions 1 and 3) change? ${ }^{11}$

As a rough estimate, in the counterfactual case without SSOs and industry associations, the level of $R \& D$ effort required to achieve a given $R \& D$ quality index would be percent of the effort required to achieve the same R\&D quality index with SSOs and industry associations.

(Responses less than 100 indicate that less effort is required to achieve a given R\&D quality index in the counterfactual case. Responses greater than 100 indicate that more effort is required in the counterfactual case.)

4. How would the value to your company - the present value to the company of the stream of future profits in the post-innovation market available to provide a return on the $R \& D$ investment - associated with a given $R \& D$ quality index change?

As a rough estimate, in the counterfactual case without SSOs and industry associations, the value of a given $R \& D$ quality index would be percent of the value of the same R\&D quality index with the SSO and industry association support.

(Responses less than 100 indicate that a given R\&D quality index is less valuable in the counterfactual case. Responses greater than 100 indicate that a given $\mathrm{R} \& \mathrm{D}$ quality index is more valuable in the counterfactual case.)

5. In Part II, Question 5 asked about the percentage of the total social value of your company's R\&D that is captured by other companies and end users. In the counterfactual case without SSOs and industry associations, would your answer to this question change? (Yes/No).

If yes, which answer? $\%$

\footnotetext{
${ }^{11}$ Note: The effort required could go down if, for example, the anticipated state-of-the-art quality is lower in the counterfactual case. The effort required could go up if, for example, it is more costly in the counterfactual case to achieve a given outcome. In the presence of such countervailing effects, it is possible for the required level of effort to rise or to fall or to remain unchanged overall.
} 


\section{Concluding Questions:}

If you would be willing to be contacted with follow-up questions, please provide an e-mail address or telephone number:

If you would like a copy of our final report, please provide an e-mail or postal address:

\section{Thank you for participating in the survey.}

Please return by email or regular mail to:

John T. Scott, Professor of Economics, john.t.scott@dartmouth.edu Department of Economics, Dartmouth College, Hanover, NH 03755 USA 